\title{
EfFicient Barriers to Trade: A Sequential Trade Model WITH HETEROGENEOUS AgENTS
}

\author{
by
}

Benjamin Eden

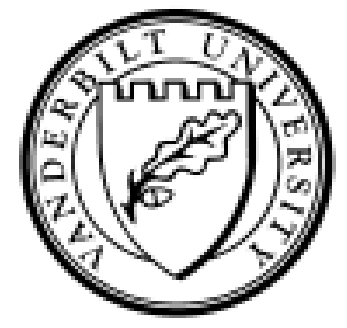

Working Paper No. 07-W02

January 2007

\section{DEPARTMENT OF ECONOMICS \\ VANDERBILT UNIVERSITY \\ NASHVILLE, TN 37235}

www.vanderbilt.edu/econ 
EFFICIENT BARRIERS TO TRADE: A SEQUENTIAL TRADE MODEL WITH HETEROGENEOUS AGENTS

Benjamin Eden

Vanderbilt University and the University of Haifa

January 2007

This paper studies a flexible price version of the Prescott (1975) hotels model. Unlike rigid price versions of the model, here the equilibrium outcome is efficient if potential buyers have the same downward sloping demand curve or if the probability of becoming active does not depend on their type. In the absence of these conditions the equilibrium outcome may not be efficient even in the second best (constrained) sense. I apply the analysis to discuss barriers to trade that are motivated by efficiency considerations. I show that a tariff, for example, may lead to Pareto improvement.

Mailing address: Department of Economics, Vanderbilt University

Box 351819B

Nashville, TN 37235-1819

E-mail: ben.eden@vanderbilt.edu 
1. INTRODUCTION

Barriers to trade are viewed in the profession as a way of protecting an industry or improving the terms of trade of one country at the expense of another country. Here I study a competitive model in which barriers to trade are motivated by efficiency considerations. I show that a tariff, for example, may lead to a Pareto improvement over the free trade outcome.

I study a version of the Prescott (1975) hotels model. In Prescott's model, sellers of motel rooms set prices before they know how many buyers will arrive. Prescott assumes that cheaper rooms are sold first and therefore in equilibrium sellers face a tradeoff between price and the probability of making a sale.

In Prescott's example all motel rooms are the same and all buyers who arrive want a single room and are willing to pay up to the same reservation price. Prescott's conclusion is that "For this example, which entails monopoly power on the part of sellers facing a stochastic demand, the competitive equilibrium is efficient. If demanders were heterogeneous (in terms of preferences) and there were heterogeneity in the type of room supplied, it is possible that these conclusions would be altered. Until such an analysis is successfully performed, I see no reason to conjecture that the natural vacancy rate is either too high or too low." (page 1233). Dana (1998) has extended the rigid price version of the Prescott's model to the case of heterogeneous potential buyers who demand at most one unit and have different valuation and different probabilities of becoming active. He shows that firms in the Prescott 
model have incentives to offer advance-purchase discounts and in equilibrium advance purchase sales are made to low valuation customers. He concludes that because of price rigidity the equilibrium allocation may not be as good as the Walrasian outcome (first best) even when buyers have a demand for one unit only. Deneckere and Peck (2005) show that once we allow for heterogeneity, the allocation is not first best. But we can achieve the first best if we allow buyers to return for a second round of trading.

A flexible price version of the Prescott model is in Eden $(1990,2005)$ and Lucas and Woodford (1993). This approach assumes that buyers arrive sequentially, see all available offers and after buying at the cheapest available offer they consume and go elsewhere. I refer to this version of the Prescott model as the Uncertain and Sequential Trade (UST) model.

From a positive economics point of view it does not matter whether prices in the model are flexible or rigid. But for the question of efficiency, which is the focus of this paper, it does matter. In the rigid price version of the Prescott model prices are set before the arrival of buyers but actual sales (and consumption) occur after all buyers arrive and the realization of demand is known. At this point sellers may want to change their price but cannot. A central planner who has the same information as the sellers in the Prescott model can achieve the Walrasian allocation. ${ }^{2}$ He will do better whenever the Walrasian allocation is different from the Prescott allocation.

2 The Walrasian allocation for our environment is described by the peak load pricing model of Williamson (1966). 
Prescott assumes that each buyer demands one unit only and therefore he gets an equilibrium allocation that is the same as the Walrasian allocation. Allowing for a more general downward sloping demand curve (per buyer) will alter the efficiency result in the Prescott model even when all buyers have the same demand function. This is because a planner that makes the actual allocation after he knows the realization of demand, will distribute the entire capacity to the first batch of buyers if he knows that the second batch will not arrive. A planner in a UST environment faces the same informational constraint as the sellers in the UST model and must therefore choose consumption for the first batch buyers before he knows whether the second batch will arrive or not. Therefore the allocation in the UST model may be efficient even when it is different from the Walrasian allocation. For this reason it is useful to think of the flexible and rigid price versions of the Prescott model as two different models, while keeping in mind that the resulting allocation is often the same in both models.

Here I generalize the flexible price version of the Prescott model (the UST model in Eden [1990]) to allow for uncertainty about the number of sellers and to allow for heterogeneous buyers. Unlike the rigid price version, efficiency does not require a single unit demand and identical potential buyers. It is shown that the UST outcome is efficient if (a) potential buyers have the same demand function or (b) if the probabilities of becoming active does not depend on the buyer's type.

This paper also complements the analysis in Eden (forthcoming) where I show that a country with a stable demand may suffer from 
trade with a country with unstable demand, there may be too much trade, a country may import and export the same good in the same period (cross-hauling) and dumping may occur. Here I use the example in Eden (forthcoming) to analyze the question of optimal barriers to trade such as subsidies, export taxes and tariffs.

2. THE MODEL

I consider an economy with two dates $(t=0,1)$ and two goods ( $\mathrm{X}$ and $\mathrm{Y}$ with lower case letters denoting quantities). There are $\mathrm{S}$ possible aggregate states of nature (indexed $\mathbf{s}$ ). There are many potential ex-ante identical sellers and out of this group actual sellers are chosen randomly. An actual seller (a seller for short) can produce as many units as he wants at the price of $\lambda$ units of $Y$ per unit of $x$. In state $s$ there are $M_{s}$ actual sellers. State $s$ occurs with probability $\Pi_{\mathrm{s}} \cdot{ }^{3}$ sellers are risk neutral and derive utility from Y only.

Unlike sellers, buyers are heterogeneous. There are J types of buyers. The number of type $j$ (potential) buyers is $n_{j}$. All buyers are endowed with a large quantity of $\mathrm{Y}$. In aggregate state s the utility function that a fraction $\phi_{j s}$ of type $j$ buyers realize is: $u_{j s}(x, y)=U_{j}(x)+y$, where $U_{j}(x)$ is strictly monotone, strictly concave and differentiable. The remaining fraction of $1-\phi_{j s}$ who are

3 The probability $\Pi_{s}$ is the probability of state $s$ from the actual sellers' point of view (conditional on being chosen as an actual seller). 
not active realize the utility function: $u_{j s}(x, y)=y$. The random utility of a type $j$ buyer in aggregate state $s$ is thus:

$$
u_{j s}(x, y)=U_{j}(x)+y \text { with probability } \phi_{j s} \text { and } y \text { otehrwise. }
$$

A type $j$ buyer demands $d_{j}(p)$ units of $x$ at the price $p$ if he wants to consume, where the individual demand function is defined by:

$$
d_{j}(p)=\operatorname{argmax}_{x \geq 0} U_{j}(x)-p x
$$

The first order condition for the problem (2) is:

$$
U_{j}^{\prime}(x) \leq p \text { with equality if } x>0 \text {. }
$$

Production (capacity choice) occurs at $t=0$. After production choice is made, buyers realize a utility function and those who want to consume form a line. I treat all buyers symmetrically and assume that any segment taken from this line accurately represents the type composition of buyers who want to consume: In state $s, \Sigma_{j} \phi_{j s} n_{j}$ buyers want to consume and the fraction of type $i$ buyers in any segment of the line is: $\phi_{i s} n_{i} / \Sigma_{j} \phi_{j s} n_{j}$. After the line is formed, buyers arrive at the market place one by one according to their place in the line and choose whether to buy at the cheapest available offer. The sequential trade does not take real time (it occurs in meta time).

I start with the relatively simple case in which all types have the same demand functions. This case is useful for making the distinction between the Prescott model and the UST model. 
2.1 BUYERS HAVE THE SAME DEMAND FUNCTIONS AND THERE IS NO UNCERTAINTY ABOUT SUPPLY

I assume that $U_{j}(x)=U(x)$ and $d_{j}(p)=d(p)$ for all $j$. To simplify, I also assume that there is no uncertainty on the supply side and $\mathrm{M}_{\mathrm{s}}=1$ for all s. I use $\mathrm{N}_{\mathrm{s}}=\Sigma_{j} \phi_{j \mathrm{~s}} \mathrm{n}_{j}$ for the number of active buyers and assume: $\mathrm{N}_{1}<\mathrm{N}_{2}<\ldots<\mathrm{N}_{\mathrm{S}}$.

The minimum number of (active) buyers is: $\Delta_{1}=\mathrm{N}_{1}$. The first batch of $\Delta_{1}$ buyers arrives with certainty. After buyers in this first batch complete trade and go away there are two possibilities. If $\mathbf{s}=1$ trade ends. If $\mathbf{s}>1$, there are $\mathrm{N}_{\mathrm{s}}-\mathrm{N}_{1}$ unsatisfied buyers. The minimum number of unsatisfied buyers if $\mathbf{s}>1$ is: $\Delta_{2}=\min _{\mathrm{s}}\left\{\mathrm{N}_{\mathrm{s}}-\mathrm{N}_{1}\right\}=\mathrm{N}_{2}-\mathrm{N}_{1}$ and this is the number of buyers in batch 2. The probability that $s>1$ is $q_{2}=1-\Pi_{1}$ and this is the probability that batch 2 will arrive. After batch 2 completes trading (and disappear) there may be again two possibilities: either no additional buyers arrive or, if $\mathbf{s}>2$, some additional buyers do arrive. The minimum number of unsatisfied buyers if $\mathrm{s}>2$ is: $\Delta_{3}=\min _{\mathrm{s}}\left\{\mathrm{N}_{\mathrm{s}}-\mathrm{N}_{2}\right\}=\mathrm{N}_{3}-\mathrm{N}_{2}$. The probability that $\mathrm{s}>2$ and the third batch of buyers will arrive is $q_{3}=1-\Pi_{1}-\Pi_{2}$. Proceeding in this way we define $\mathrm{q}_{\mathrm{s}}$ and $\Delta_{\mathrm{s}}$ for all $\mathrm{s}=1, \ldots, \mathrm{s}$.

The seller is a price-taker and behaves as if he can sell any amount at the price $P_{i}$ to buyers in batch $i$ if it arrives. It is convenient to think of a sequence of Walrasian markets, where batch $i$ buys in market $i$ and the seller supplies $x_{i}$ units to market $i$. 
Because of constant returns to scale equilibrium prices are determined by supply conditions only. The expected revenue from supplying a unit to market $i$ is $q_{i} P_{i}$. When $q_{i} P_{i}=\lambda$ the expected profit is zero regardless of the quantity supplied. Therefore equilibrium prices must satisfy $q_{i} P_{i}=\lambda$.

I now define equilibrium as follows.

Equilibrium is a vector of prices $\left(\mathrm{P}_{1}, \ldots, \mathrm{P}_{\mathrm{S}}\right)$ and a vector of supplies $\left(\mathrm{x}_{1}, \ldots, \mathrm{x}_{\mathrm{S}}\right)$ such that:
(a) $\mathrm{P}_{\mathrm{i}}=\lambda / \mathrm{q}_{\mathrm{i}}=\lambda / \sum_{s=i}^{S} \Pi_{s}$ and
(b) $x_{i}=\left(N_{i}-N_{i-1}\right) d\left(P_{i}\right)=\Delta_{i} d\left(P_{i}\right)$.

Thus in equilibrium markets that open are cleared. Note that (posted) prices may appear rigid because they do not respond to the realization of demand (the state). Nevertheless, it is shown in the Appendix that sellers' contingent selling plan is time consistent and they do not have an incentive to change prices during trade. To solve for the equilibrium quantities we substitute the equilibrium condition (a) in (b) to get:

$$
x_{i}=\Delta_{i} d\left(\lambda / q_{i}\right)
$$

To characterize the welfare properties of equilibrium, I consider a UST planner (to be distinguished from a Walrasian planner) who can observe the number of batches that already have arrived (the quantity sold). The planner chooses the amount $y_{i}$ that will be 
delivered to a buyer that arrives in batch $i$ to maximize the expected sum of utilities by solving:

$$
\max _{y_{i}} \sum_{i=1}^{S} q_{i} \Delta_{\mathrm{i}} \mathrm{U}\left(\mathrm{y}_{\mathrm{i}}\right)-\lambda \sum_{i=1}^{S} \Delta_{i} y_{i}
$$

I now show a version of Theorem 1 in Eden (1990).

Proposition 1: The equilibrium allocation $y_{i}=d\left(\lambda / q_{i}\right)$ is a solution to $(5)$.

The Proof of Proposition 1 as well as all other Proofs is in the Appendix.

Although the UST outcome is efficient it is not the same as the Walrasian outcome. In a Walrasian equilibrium all buyers face the same price and since they all have the same demand they get the same quantity. In the UST model buyers who arrive first face a lower price and buy a larger quantity. The two allocations are the same only in the special case in which each buyer demands one unit only. Since the Walrasian auctioneer knows the state, the Walrasian outcome is in general better than the UST outcome. In the Appendix I show the following Proposition.

Proposition 2: Whenever the Walrasian outcome is different from the UST outcome, it is better.

I now turn to another relatively simple case. 
2.2 THE PROBABILITY OF BECOMING ACTIVE DOES NOT DEPEND ON THE BUYER'S TYPE

As before, I assume that the number of sellers is known and $\mathrm{M}_{\mathrm{s}}=1$ for all $\mathrm{s}$. Potential buyers may have different demand functions but the probability of becoming active depends only on the aggregate state and not on the buyer's type: $\phi_{j s}=\phi_{s}$ for all $j$. I choose indices so that demand is increasing in the state: $0=\phi_{0} \leq \phi_{1} \leq \ldots \leq \phi_{\mathrm{S}}=1$.

In state $\mathrm{s}$, the number of active buyers is $\mathrm{N}_{\mathrm{s}}=\phi_{\mathrm{s}} \mathrm{N}$ where $N=\Sigma_{j} n_{j}$ is the number of potential buyers. The fraction of type $j$ buyers in any segment of the line is $\phi_{s} n_{j} / \phi_{s} N=n_{j} / N$ and is independent of $\mathrm{s}$. We can therefore compute the demand of each batch without knowing the state.

The minimum number of buyers that will arrive is $\phi_{1} \mathrm{~N}$ and the demand of this first batch (at the price p) is: $D_{1}(p)=\phi_{1} \Sigma_{j} n_{j} d_{j}(p)$ units. If $\mathbf{s}>1$ a second batch of $\left(\phi_{2}-\phi_{1}\right) \mathrm{N}$ buyers will arrive and demand: $D_{2}(p)=\left(\phi_{2}-\phi_{1}\right) \Sigma_{j} n_{j} d_{j}(p)$ units. In general, the demand of batch $i$ at the price $p$ is: $D_{i}(p)=\left(\phi_{i}-\phi_{i-1}\right) \Sigma_{j} n_{j} d_{j}(p)$.

Equilibrium is a vector of prices $\left(\mathrm{P}_{1}, \ldots, \mathrm{P}_{\mathrm{S}}\right)$ and a vector of supplies $\left(\mathrm{x}_{1}, \ldots, \mathrm{x}_{\mathrm{S}}\right)$ such that:

(a) $\mathrm{P}_{\mathrm{i}}=\lambda / \mathrm{q}_{\mathrm{i}}=\lambda / \sum_{s=i}^{S} \Pi_{s}$ and

(b) $x_{i}=D_{i}\left(P_{i}\right)$.

In equilibrium a type $j$ buyer who arrives in batch $i$ consumes $\mathrm{d}_{j}\left(\lambda / \mathrm{q}_{i}\right)$ units. To characterize the efficiency properties of the 
equilibrium allocation I consider a social planner who observes the number of batches that have already arrived (or the total number of units already sold) and the buyers' type. I thus assume a more "powerful" planner than in the previous same demand case (more discussion is provided later).

The social planner allocates $y_{j i}$ units to a type $j$ buyer who arrives in batch $i$. He chooses these quantities to maximize the expected sum of utilities:

$$
\max _{y_{j i}} \sum_{i=1}^{S} q_{i}\left(\phi_{i}-\phi_{i-1}\right) \sum_{j=1}^{J} n_{j} U_{j}\left(y_{j i}\right)-\lambda \sum_{i=1}^{S} \sum_{j=1}^{J} y_{j i}\left(\phi_{i}-\phi_{i-1}\right) n_{j} \cdot
$$

In the Appendix we show the following Proposition.

Proposition 3: The equilibrium allocation $y_{j i}=d_{j}\left(\lambda / q_{i}\right)$ solves (6).

Thus, the assumption that the probabilities of becoming active are not type-dependent is sufficient for efficiency. Note that this is efficiency in the second best (constrained) sense. If the planner had the information about the state at the beginning of trade, he would have administered the Walrasian (Peak-Load-Pricing) allocation. I now turn to the general case in which potential buyers have different demand functions and the probability of becoming active is type-dependent. 


\subsection{THE GENERAL CASE}

As before buyers arrive in batches but here the size of each batch is endogenous. I now turn to describe an algorithm for computing the size of each batch for an arbitrarily chosen price $\operatorname{vector}\left(P_{1} \leq P_{2} \leq \ldots \leq P_{S}\right)$.

Roughly speaking, the size of the first batch is the minimum demand at the price $P_{1}$. Market 2 opens if there are some buyers who wanted to buy in the first market but could not. In general, market $i$ opens if there is residual demand after transactions in market i-1 are complete. The size of batch $i$ is the minimum residual demand per seller. We now turn to a detailed description of this algorithm. Demand per seller in state $\mathbf{s}$ at the price $\mathrm{P}_{1}$ is: $\sum_{j} \phi_{j s} n_{j} d_{j}\left(P_{1}\right) / M_{s}$. We choose indices such that state 1 is the state of minimum demand, $1=\operatorname{argmin}_{s}\left\{\sum_{j} \phi_{j s} n_{j} d_{j}\left(P_{1}\right) / M_{s}\right\}$. The per seller demand of buyers in the first batch is: $D_{1}\left(P_{1}\right)=\Sigma_{j} \phi_{j 1} n_{j} d_{j}\left(P_{1}\right) / M_{1}$ units. It is assumed that each seller supplies that many units at the price $\mathrm{P}_{1}$. If $\mathbf{s}=1$ then all buyers are served in the first market and trade ends. Otherwise, if $s>1$, a demand for $\Sigma_{j} \phi_{j s} n_{j} d_{j}\left(P_{1}\right)-M_{s} D_{1}\left(P_{1}\right) \geq 0$ units was not satisfied. The fraction of demand satisfied in market 1 is:

$1-\chi_{s}^{1}\left(P_{1}\right)=M_{s} D_{1}\left(P_{1}\right) / \Sigma_{j} \phi_{j s} n_{j} d_{j}\left(P_{1}\right)$. The residual demand per seller at the price $P_{2}$ is $\chi_{s}^{1}\left(P_{1}\right) \Sigma_{j} \phi_{j s} n_{j} d_{j}\left(P_{2}\right) / M_{s}$. We now choose the indices $\mathrm{s}>1$ so that $2=\operatorname{argmin}_{\mathrm{s}>1}\left\{\chi_{s}^{1}\left(\mathrm{P}_{1}\right) \Sigma_{j} \phi_{j \mathrm{~s}} \mathrm{n}_{j} \mathrm{~d}_{j}\left(\mathrm{P}_{2}\right) / \mathrm{M}_{\mathrm{s}}\right\}$ and the minimum residual demand per seller is in state 2 . The demand of buyers in batch 2 is: $D_{2}\left(P_{1}, P_{2}\right)=\chi_{2}^{1}\left(P_{1}\right) \Sigma_{j} \phi_{j 2} n_{j} d_{j}\left(P_{2}\right) / M_{2}$ units. 
In general, we start iteration i having already computed the fraction $\mathrm{Z}_{s}^{i-2}$ of demand that was not satisfied in markets $1, \ldots, i-2$. For example, if $i=3$ we already know the fraction of demand that was not satisfied in market $1: \mathrm{Z}_{s}^{i-2}=\chi_{s}^{1}\left(\mathrm{P}_{1}\right)$. We have also computed the amount per seller supplied to market i-1: $D_{i-1}\left(P_{1}, \ldots, P_{i-1}\right)$. If $s>i-1$, the demand in market $i-1$ is: $\mathrm{Z}_{s}^{i-2} \Sigma_{j} \phi_{j \mathrm{~s}} \mathrm{n}_{j} \mathrm{~d}_{j}\left(\mathrm{P}_{\mathrm{i}-1}\right)$. The supply to this market is: $\mathrm{M}_{\mathrm{s}} \mathrm{D}_{\mathrm{i}-1}\left(\mathrm{P}_{1}, \ldots, \mathrm{P}_{\mathrm{i}-1}\right)$. The fraction of the residual demand satisfied in market i-1 is:

$$
1-\chi_{s}^{i-1}\left(\mathrm{P}_{1}, \ldots, \mathrm{P}_{\mathrm{i}-1}\right)=\mathrm{M}_{\mathrm{s}} \mathrm{D}_{\mathrm{i}-1}\left(\mathrm{P}_{1}, \ldots, \mathrm{P}_{\mathrm{i}-1}\right) / \mathrm{Z}_{s}^{i-2} \Sigma_{j} \phi_{j s} \mathrm{n}_{\mathrm{j}} \mathrm{d}_{\mathrm{j}}\left(\mathrm{P}_{i-1}\right) .
$$

The fraction of buyers who could not buy in markets $1, \ldots, i-1$ is: $\mathrm{Z}_{s}^{i-1}=\mathrm{Z}_{s}^{i-2} \chi_{s}^{i-1}$. When $\mathrm{s}>\mathrm{i}-1$, the residual demand per seller at the price $P_{i}$ is: $Z_{s}^{i-1} \Sigma_{j} \phi_{j s} n_{j} d_{j}\left(P_{i}\right) / M_{s}$. We choose indices $s>i-1$ such that: $i=\operatorname{argmin}_{s>i-1}\left\{Z_{s}^{i-1} \sum_{j} \phi_{j s} n_{j} d_{j}\left(P_{i}\right) / M_{s}\right\}$. The demand per seller in batch i is:

$$
D_{i}\left(P_{1}, \ldots, P_{i}\right)=Z_{i}^{i-1} \Sigma_{j} \phi_{j i} n_{j} d_{j}\left(P_{i}\right) / M_{i},
$$

units.

Given the construction of the demand functions $D_{i}\left(P_{1}, \ldots, P_{i}\right)$ we can now define a symmetric equilibrium as follows.

A UST equilibrium is a vector of prices $\left(P_{1}, \ldots, P_{S}\right)$ and a vector of per seller supplies $\left(x_{1}, \ldots, x_{s}\right)$ such that:

(a) $P_{i}=\lambda / q_{i}$ and

(b) $x_{i}=D_{i}\left(P_{1}, \ldots, P_{i}\right)$. 
In equilibrium the seller must know prices and all sellers must coordinate on the supply to each of the $\mathrm{S}$ potential market. We may describe equilibrium in the following way. Each seller puts a price tag of $\mathrm{P}_{i}$ on $\mathrm{x}_{\mathrm{i}}$ units and then remains passive. He knows that the lowest priced $x_{1}$ units will be sold first with certainty. Then if there are additional demand (with probability $\mathrm{q}_{2}$ ) the $\mathrm{x}_{2}$ units with the price tag $P_{2}$ will be sold and so on. The seller does not use the type composition of batch $i$ to update the probabilities of the states. But the amount that is sold to each buyer is type dependent. We may therefore think of the seller as having many outlets and since trade does not take real time he cannot get aggregate statistics on the type composition during trade.

The UST planner:

To characterize the efficiency properties of the UST equilibrium, I assume an hypothetical planner who operates in the same environment as the sellers in the model and, roughly speaking, has the minimal amount of information required for executing the equilibrium allocation.

The planner meets all potential sellers and tells them how much to produce and how to allocate their output if they become active. He instructs each seller to distribute (if he becomes active) the first $y_{1}$ units by giving each type $j$ buyer that arrives, the quantity $y_{j 1}$. It is possible that the seller will not distribute all the $\mathrm{y}_{1}$ units because the line of active buyers is too short. It is also possible that when the seller distributes all the $y_{1}$ units there are no buyers 
left in the line. If however there are some buyers who are still in line, the seller is instructed to distribute an additional quantity of $y_{2}$ units by giving each type $j$ buyer that arrives a quantity of $y_{j 2}$ units. If after distributing the additional $y_{2}$ units there are still buyers in the line he is instructed to supply additional $y_{3}$ units by giving each type $j$ buyer that arrives a quantity of $y_{j 3}$ units and so on. Thus, the $y_{i}$ play the role of the equilibrium supply $x_{i}$ and the $y_{j i}$ play the role of $d_{j}\left(P_{i}\right)$.

We may think of hypothetical markets that are defined by the per seller quantities supplied: The quantity $y_{i}$ is supplied to market i. The planner's instructions are to distribute $y_{j i}$ units to any type $j$ buyer who arrives in market $i$. Since we assume that there are many outlets per seller and trade does not take real time, the planner cannot receive aggregate statistics on the type composition of each batch and similar to the sellers in the model, he does not use the type composition of the buyers in each batch to update the probability of the state.

I now turn to compute the number of type $j$ buyers served in market $i$ as a function of the state. The fraction of type $j$ buyers who are in any segment of the line is: $\psi_{j s}=\frac{\phi_{j s} n_{j}}{\sum_{m} \phi_{m s} n_{m}}$.

The average quantity per buyer served in market i is: $A_{i s}=\sum_{j} \psi_{j s} y_{j i}$. The number of buyers served in market $i$ is: $\Delta_{i s}=\frac{y_{i}}{A_{i s}}$. The number of type $j$ buyers served in market $i$ is:

$$
0 \leq \Delta_{j i s}=\psi_{j s} \Delta_{i s}=\frac{\psi_{j s} y_{i}}{A_{i s}}=\frac{\psi_{j s} y_{i}}{\sum_{m} \psi_{m s} y_{m i}}<\infty
$$


The planner must also keep the line moving by choosing:

$$
y_{j i} \leq y_{j i-1}
$$

Under (10) there is no incentive to wait. Finally the planner has to service (possibly with $y_{j i}=0$ ) all the buyers who want to consume:

$$
\sum_{i=1}^{s} \Delta_{j i s}=\phi_{j s} n_{j} \text { for all } j \text { and } s .
$$

The planner chooses $y_{i}$ and $y_{j i}$ that solve the following maximization problem:

$$
\max _{y_{i}, y_{j i}} \sum_{i=1}^{S} \sum_{s=i}^{S} \Pi_{s} \sum_{j=1}^{J} \Delta_{j i s} U_{j}\left(y_{j i}\right)-\lambda \sum_{i=1}^{S} y_{i} \quad \text { s.t. (9) }-(11) \text {. }
$$

In general the UST allocation is not a solution to the planner's problem (12). The reason is in the lack of ex-ante full contingent markets for allocating capacity.

Note that the planner's problem may be stated in terms of prices rather than quantities. The planner may choose type specific prices $P_{j i}$ such that $y_{j i}=d_{j}\left(p_{j i}\right)$. The planner puts the price tag $p_{j i}$ on $y_{j i}$ units and then remains passive. He knows that the lowest priced $\mathrm{y}_{1}=\Sigma_{j} \mathrm{y}_{j 1}$ units will be sold first with certainty. Then if there are additional demand (with probability $\mathrm{q}_{2}$ ) the $\mathrm{y}_{j 2}$ units with the price tags $\mathrm{p}_{j 2}$ will be sold and so on. Thus the planner is more powerful than the sellers in the model because he can charge type 
specific prices. This assumption is quite realistic if buyers from type $j$ reside in country $j$ as we are going to assume.

I now turn to an example in which subsidies, export taxes and tariffs are used to achieve an allocation that is close to the planner's solution.

Example: I assume two states of nature with equal probability of occurrence. There is a known number of sellers and two types of buyers: Type 1 wants to consume in both states; type 2 wants to consume only in state 2. Type 1 resides in country 1 and type 2 resides in country 2 . I also assume: $n_{1}=n_{2}=1 ; \lambda=1$; $\mathrm{U}_{1}(\mathrm{x})=20 \ln (\mathrm{x}) ; \mathrm{U}_{2}(\mathrm{x})=10 \ln (\mathrm{x}) ; \mathrm{d}_{1}(\mathrm{p})=20 / \mathrm{p} ; \mathrm{d}_{2}(\mathrm{p})=10 / \mathrm{p}$

UST autarky: Under autarky in country 1 there is only one market that opens with certainty. The price in this market is 1 and the supply to this market is 20. The surplus is: $20 \ln (20)-20=39.915$.

Under autarky in country 2 there is one market that opens with probability $1 / 2$. The price in this market is 2 and the quantity demanded is 5. Welfare is: $(1 / 2) 10 \ln (5)-5=3.047$.

Free trade: The price in the first market is 1 and the price in the second market is 2 . Twenty units are supplied to the first market.

In the high demand state the average demand is $(1 / 2)(20 / 1)+(1 / 2)(10 / 1)=15$ per buyer and $20 / 15=4 / 3$ buyers will be serviced. The remaining $2 / 3$ buyers will buy at the price 2 . At this price the average demand is: $(1 / 2)(20 / 2)+(1 / 2)(10 / 2)=7.5$ per buyer. The quantity supplied to the second market is: 
$(2 / 3) 7.5=5$. Thus the quantities supplied are the same as under autarky but the distribution of surpluses is different.

The surplus for buyers in country 1 is:

$(1 / 2)[20 \ln (20)-20]+(1 / 2)\{(2 / 3)[20 \ln (20)-20]+(1 / 3)[20 \ln (10)-20]\}=37.604$.

Surplus in country 2 is:

$(1 / 2)\{(2 / 3)[10 \ln (10)-10]+(1 / 3)[10 \ln (5)-10]\}=5.358$.

Total surplus is the same as under autarky: $37.604+5.358=42.962$.

UST planner: It is simpler to think of a planner who chooses prices rather than quantities. The planner chooses the price that he will charge in the first market from type 1 buyers $\left(p_{11}\right)$ and from type 2 buyers $\left(\mathrm{p}_{21}\right)$. The price in market 2 is $\mathrm{p}_{12}=\mathrm{p}_{22}=2$. The rest is as follows. In the low demand state type 1 buys all the supply to market 1 and therefore: $\mathrm{y}_{1}=20 / p_{11}$. In the high demand state the average demand per buyer in the first market is: $\mathrm{A}=(1 / 2)\left(20 / p_{11}\right)+(1 / 2)\left(10 / p_{21}\right)$. The number of buyers served in the first market is: $\Delta=\frac{y_{1}}{A}=\frac{2 y_{1}}{\left(20 / p_{11}\right)+\left(10 / p_{21}\right)}$. In state 2 the fraction of buyers who buy in market 1 is: $\theta=\frac{\Delta}{2}=\frac{\left(20 / p_{11}\right)}{\left(20 / p_{11}\right)+\left(10 / p_{21}\right)}$. The fraction of buyers who buys in market 2 is: $1-\theta=1-\frac{\left(20 / p_{11}\right)}{\left(20 / p_{11}\right)+\left(10 / p_{21}\right)}=\frac{\left(10 / p_{21}\right)}{\left(20 / p_{11}\right)+\left(10 / p_{21}\right)}$.

At the price of 2, the demand of a type 1 buyer is 10 and the demand of a type 2 buyer is 5. The quantity in market 2 is therefore: $(1-\theta)(10+5)$. We may therefore write the planner's problem as: 


$$
\begin{gathered}
\max _{p_{11}, p_{21}} 20 \ln \left(\frac{20}{p_{11}}\right)+\frac{\left(20 / p_{11}\right)}{\left(20 / p_{11}\right)+\left(10 / p_{21}\right)}\left[20 \ln \left(\frac{20}{p_{11}}\right)+10 \ln \left(\frac{10}{p_{21}}\right)\right] \\
+\frac{\left(10 / p_{21}\right)}{\left(20 / p_{11}\right)+\left(10 / p_{21}\right)}[20 \ln (10)+10 \ln (5)]-2\left[\frac{20}{p_{11}}+\frac{\left(10 / p_{21}\right) 15}{\left(20 / p_{11}\right)+\left(10 / p_{21}\right)}\right]
\end{gathered}
$$

The first term in (13) is the utility of type 1 agents in state 1. The next two terms are the sum of utilities when demand is high. The last term is (twice) the cost of producing $y_{1}+y_{2}$. The solution to $(13)$ is: $\mathrm{p}_{11}=0.92$ and $\mathrm{p}_{21}=1.71$. The planner can thus improve on the competitive allocation by choosing $y_{1}=20 / 0.92=21.739$. He then charges 0.92 from each type 1 buyer and 1.71 from each type 2 buyers. In state 1 all type 1 buyers are serviced at the price of 0.92 . In state $2,0.788$ of the buyers are serviced in market 1 and the remaining 0.212 are serviced in market 2. Aggregate surplus for the planner's solution is 43.682 which is higher than the aggregate surplus under free trade.

\section{Tariffs, Export Taxes and Subsidies:}

I start by assuming that the government in country 2 is passive. The government in country 1 chooses a subsidy of $\sigma>0$ for the good bought from local producers and an export tax of $\tau>0$.

In equilibrium, sellers from country 2 specialized in the second market and only sellers from country 1 supply to the first market. I now describe the equilibrium in detail. Zero expected profits requires that sellers get a price of 1 in market 1 and a price of 2 in market 2 . In the proposed equilibrium sellers in market 
2 sell at the price of 2 and this is the price paid by buyers in market 2 . In market 1 there are differences between the producer and the consumer prices due to the subsidy and export tax. Buyers from country 1 who make it to the first market buy at the price of $1-\sigma$ and buyers from country 2 who make it to the first market buy at the price of $1+\tau$.

We now check that in the proposed equilibrium, sellers from country 2 cannot increase expected profits by selling in market 1. Since buyers from country 1 who buy from local sellers pay 1 - $\sigma$, sellers in country 2 can insure sale only if they offer the good at the price of $1-\sigma$. Since this is less than the expected price in the second market they choose to specialize in the second market. The equilibrium supply to market 1 is:

$$
y=\frac{20}{1-\sigma}
$$

This is also the demand per country 1 buyer in market 1 . In the high demand state (state 2) buyers from country 2 who make it to the first market will buy the good at the price of $1+\tau$. The demand per country 2 buyer in the first market is therefore: $\frac{10}{1+\tau}$. The average demand per buyer in market 1 is: $A=(1 / 2)\left(\frac{20}{1-\sigma}+\frac{10}{1+\tau}\right)$. The number of buyers serviced in market 1 is : $\Delta=\frac{y}{A}=\frac{40(1+\tau)}{20(1+\tau)+10(1-\sigma)}$. The fraction of buyers who buy in market 1 is:

$$
\theta=\Delta / 2=\frac{20(1+\tau)}{20(1+\tau)+10(1-\sigma)}
$$


Government revenues from the export tax in state 2 are:

$$
g=\tau\left(\frac{10}{1+\tau}\right) \theta
$$

Export revenues in state 2 are:

$$
\mathrm{EX}=\left(\frac{10}{1+\tau}\right) \theta
$$

The government in country 1 will choose $\tau$ and $\sigma$ by solving:

$$
\begin{gathered}
\max _{\tau, \sigma}\left[\mathrm{U}_{1}(\mathrm{y})-\mathrm{y}\right]+\left[\theta \mathrm{U}_{1}(\mathrm{y})+\mathrm{g}+\mathrm{EX}-\mathrm{y}\right] \\
+(1-\theta)\left[\mathrm{U}_{1}(10)-20\right] \\
\text { s.t. }(14)-(17) \text { and } 0 \leq \sigma, \tau \leq 1 .
\end{gathered}
$$

The first term in (18) is the surplus (of country 1) in the low demand state. The next two terms are the surplus in the high demand state. The first term is the surplus from the operation of market 1 in state 2 . The second is the surplus that a fraction $1-\theta$ of country 1 buyers get from buying in market 2 .

The objective function in (18) is strictly increasing in $\tau$ and therefore $\tau=1$ will be chosen. The first order condition that an interior solution $0<\sigma<1$ has to satisfy is:

(19) $\mathrm{Y}^{\prime}\left[\mathrm{U}_{1}^{\prime}(1+\theta)-2\right]+\theta^{\prime}\left\{\mathrm{U}(\mathrm{y})-\left[\mathrm{U}_{1}(10)-20\right]\right\}+\left[\mathrm{g}^{\prime}+\mathrm{EX}\right]=0$

The left hand side of (19) is the effect of an increase in $\sigma$ on social surplus. This can be divided into three terms. The first term, $\mathrm{y}^{\prime}\left[\mathrm{U}_{1}{ }^{\prime}(1+\theta)-2\right]$, is the effect on the amount consumed in the first 
market by a type 1 buyer. This term is negative because $y^{\prime}>0$ and the first order condition of the buyer implies $U_{1}^{\prime}=1-\sigma<1$. The second, $\theta^{\prime}\left\{U(y)-\left[U_{1}(10)-20\right]\right\}$, is the effect on the fraction of buyers who make a buy in the first market in the high demand state. Since $\theta^{\prime}>0$ and $y>10$, this term is positive. The last is the effect on revenues from foreigners in the high demand state. Since $\theta^{\prime}>0$, this term is also positive.

The solution to (18) is: $\tau=1, \sigma=0.073$. Relative to autarky, this choice of export tax and subsidy will increase surplus in country 1 (from 39.915 to 40.587 ), will not change the surplus in country 2 and will increase aggregate world surplus by roughly 1.5 percent: from 42.962 to 43.634 .

Using an export tax of 1 as a threat, the government in country 1 may negotiate with country 2 to reduce the export tax to the efficient level of 0.71 for a lump sum payment that will keep the welfare in country 2 close to its autarkic level. This will result in a welfare measure of 40.635 for country 1 . I now turn to the case in which government 2 is active.

Government 1 is passive and government 2 impose a tariff:

I now assume that the government in country 2 imposes a tariff and a small export tax while the government in country 1 is passive. ${ }^{4}$ I use $\eta$ to denote the tariff and $\tau$ to denote the export tax. As before, seller 2 specializes in market 2. The producers' prices are 1

4 The export tax may not be needed if there are some transportation costs as in Eden (forthcoming). 
in market 1 and 2 in market 2. In market 1 buyer 1 pays 1 and buyer 2 pays $1+\eta$. In market 2 both buyers pay 2 . Since seller 2 can sell in market 1 at the price $1-\tau$ that is less than the expected price in market 2 , he will choose to specialize in market 2 .

The amount that will be bought by a type 2 buyer in market 1 is :

$$
z(\eta)=\frac{10}{1+\eta}
$$

The amount that will be bought by a type 1 buyer in market 1 is 20 . The average demand per buyer in market 1 (high demand state) is: $A=(1 / 2)(20+z)$. The number of buyers serviced in market 1 is: $\Delta=\frac{y_{1}}{A}=\frac{40(1+\eta)}{20(1+\eta)+10}$. The fraction of buyers who buy in market 1 is:

$$
\theta(\eta)=\Delta / 2=\frac{20(1+\eta)}{20(1+\eta)+10}
$$

The policy maker in country 2 will choose $\eta$ by solving:

$$
\max _{\eta} \theta\left[\mathrm{U}_{2}(\mathrm{z})-\mathrm{z}\right]+(1-\theta)\left[\mathrm{U}_{2}(5)-10\right] \text { s.t. }(20) \text { and }(21)
$$

The first term in (22) is the social surplus from a buyer who makes a buy in market $1, \mathrm{U}_{2}(\mathrm{z})-\mathrm{z}$, times the number of buyers in market $1, \theta$. The second term is the social surplus from a buyer in market 2 times the number of buyers in this market.

The first order condition for (22) is: 


$$
\theta^{\prime}\left\{\left[U_{2}(z)-z\right]-[U(5)-10]\right\}=-\theta z^{\prime}\left[U_{2}{ }^{\prime}(z)-1\right]
$$

The intuition for (23) is as follows. An additional buyer in market 1 increases the social surplus by $U_{2}(z)-z$ units. An additional buyer in market 2 increases the social surplus by $\mathrm{U}(5)$ - 10 units. Moving a buyer from market 2 to market 1 increases the social surplus by the difference: $\left[U_{2}(z)-z\right]-[U(5)-10]$. An increase in $\eta$ by a unit leads to an increase in the fraction of country 2 buyers that buy in the first market by $\theta^{\prime}>0$. Roughly speaking the left hand side of (23) is the number of buyers that will move from the second to the first market in response to a unit increase in $\eta$ times the social benefit of moving one buyer. The left hand side of (23) is the gain from increasing $\eta$. To understand the right hand side note that $-z^{\prime}>0$ is the decrease in the amount bought by a buyer in market 1 as a result of a unit increase in $\eta$. At the margin the social surplus of a unit bought in market 1 is: $\mathrm{U}_{2}{ }^{\prime}(z)-1$. The right hand side is therefore the marginal social cost of increasing $\eta$ per buyer $-z^{\prime}\left[U_{2}{ }^{\prime}(z)-1\right]$ times the number of buyers in the first market $(\theta)$. The right hand side is therefore the cost or pain of increasing $\eta$ and (23) says that at the optimum the gain must equal the pain.

The solution to $(22)$ is: $\eta=0.24$. Table 1 summarizes the results obtained for the above example. 
Table 1: Surpluses in the example

$$
\text { Country } 1 \quad \text { Country } 2 \quad \text { Aggregate }
$$

Two states with equal probabilities. Type 1 wants to consume in both states, type 2 wants to consume in state 2 only. $\mathrm{U}_{1}(\mathrm{x})=20 \ln (\mathrm{x}) ; \mathrm{U}_{2}(\mathrm{x})=10 \ln (\mathrm{x}) ; \lambda=1$

$\begin{array}{llll}\text { Autarky } & 39.915 & 3.047 & 42.962 \\ \text { Free Trade } & 37.604 & 5.358 & 42.962\end{array}$

Planner : $\mathrm{p}_{11}=0.92$ and $\mathrm{p}_{21}=1.71$ (planner's surplus $=0.08$ )

$$
39.936 \quad 3.664 \quad 43.682
$$

Gov. 1 active (Gov. 2 passive): subsidy $=0.073$, export tax $=1\left(\mathrm{p}_{11}=0.927\right.$ and $\mathrm{p}_{21}=2$ )

$$
40.587 \quad 3.047 \quad 43.634
$$

Gov. 2 active (Gov. 1 passive): tariff $0.24\left(\mathrm{p}_{11}=1\right.$ and $\mathrm{p}_{21}=1.24$ )

Note that when government 2 imposes tariff we get a Pareto improvement. When government 2 is passive and government 1 is active we get an increase in aggregate world's surplus. This is also the case if we can charge type specific prices as in the planner's problem.

\section{CONCLUSIONS}

In this paper we distinguished between the flexible price version of the Prescott (1975) model and the fixed price version of this model. While the outcome does not depend on the price rigidity assumption the welfare implications do depend on this assumption. If prices are rigid a planner can easily improve on the Prescott allocation. This occurs even in the case of homogeneous buyers who 
have a downward sloping demand function (as opposed to a single unit inelastic demand function). In this case, a planner who observes the state will distribute more to buyers who arrive early if he knows that this is a state of low demand.

The issue is more complicated in the UST model that is a flexible price version of Prescott (1975). In this model, sellers must make irreversible trades before they know the state. A planner that operates in the same environment as the sellers in the model cannot improve matters if buyers have the same demand functions or if the probability of becoming active is type independent.

In general however, the UST outcome is not efficient. A planner who can charge type specific prices may improve matters. Tariffs, export taxes and subsidies to local producers may be viewed as a way of approximating type specific prices. In the example we worked out, a tariff leads to Pareto improvement and a combination of subsidy and export tax leads to increase in aggregate world's surplus.

The model suggests that similar countries may have less of an incentive to construct barriers to trade between them where similarity is defined by the utility function and the probability of becoming active. Although the model is highly abstract, this prediction cannot be easily rejected. 
APPENDIX : PROOFS

Claim: The Sellers' plan is time consistent.

To show this claim we apply Bayes' rule and compute the probability that market $i>s$ will open given that market $\mathbf{s}$ opens. This is: $\Pi_{i} / q_{s}$. The probability that market $i$ will open given that market $s$ opens is: $\sum_{j=i}^{S} \Pi_{j} / q_{s}$. In equilibrium the unconditional expected revenue (from a unit supplied to market i) is $\mathrm{P}_{i} \sum_{j=i}^{S} \Pi_{j}=\lambda$ and the conditional expected revenue (from a unit supplied to market $i$ given that market $\mathrm{s}$ opens) is: $\mathrm{P}_{i} \sum_{j=i}^{S} \Pi_{j} / \mathrm{q}_{\mathrm{s}}=\lambda / \mathrm{q}_{\mathrm{s}}$. Since in equilibrium $\mathrm{P}_{\mathrm{s}}$ $=\lambda / q_{s}$ the opening of market $s$ does not provide an incentive for the firm to move units from market s to market $i$ or vice versa. Since the conditional expected revenue is $\lambda / q_{s}$ for all

$i>s$, the firm does not have an incentive to move units allocated to markets $s+1, \ldots, \mathrm{S}$. Thus, not surprisingly the initial plan is time consistent.

Proof of Proposition 1: The first order condition for the problem (5) is :

$$
q_{i} U^{\prime}\left(y_{i}\right) \leq \lambda \text { with equality if } y_{i}>0
$$

Substituting $P_{i}=\lambda / q_{i}$ in the first order condition (3) leads to:

$$
q_{i} U^{\prime}\left[d\left(\lambda / q_{i}\right)\right] \leq \lambda \text { with equality if } d_{j}\left(\lambda / q_{i}\right)>0
$$


In equilibrium $y_{i}=d\left(\lambda / q_{i}\right)$ and therefore (A2) implies that the UST equilibrium allocation satisfies (A1). Since (A1) is both sufficient and necessary condition for a solution to the problem (5), the UST equilibrium allocation is a solution to (5).

Proof of Proposition 2: Let $y_{\text {is }}$ denotes the amount that the social planner will give to buyers in batch $i$ in state $s$. We may write the planner's problem in the UST environment (5) as:

$$
\begin{gathered}
\max _{y_{i s}} \sum_{s=1}^{S} \Pi_{s} \sum_{i=1}^{s} \Delta_{i} U\left(y_{i s}\right)-\lambda \max _{s}\left\{\sum_{i=1}^{s} \Delta_{i} y_{i s}\right\} \\
\text { s.t. } \mathrm{y}_{\text {is }}=\mathrm{y}_{\mathrm{i}} \text { for all } \mathrm{s} .
\end{gathered}
$$

We may write the planner's problem in a Walrasian environment as (A3) without the constraints. Therefore a planner in a Walrasian environment can achieve a better outcome than a planner in a UST environment.

Proof of Proposition 3: The first order condition for the planner's problem (6) is:

$$
q_{i} U_{j}^{\prime}\left(y_{j i}\right) \leq \lambda \text { with equality if } y_{j i}>0
$$

The first order condition for the consumer's problem (A2) ensures that in equilibrium (A4) is satisfied. Thus the UST allocation solves the planner's problem (6). 
REFERENCES

Dana James D. Jr. "Advance-Purchase Discounts and Price

Discrimination in Competitive Markets" Journal of Political

Economy, Vol.106, Number 2, April 1998, 395-422.

Deneckere Raymond and James Peck., "Dynamic Competition with Random Demand and Costless Search: A Theory of Price Posting". mimeo, July $12,2005$.

Eden, Benjamin. A Course in Monetary Economics: Sequential Trade, Money, and Uncertainty, Blackwell Publishing, 2005. "Marginal Cost Pricing When Spot Markets are Complete" Journal of Political Economy, Dec. 1990. Vol. 98, No.6,12931306 .

"Inefficient Trade Patterns: Excessive trade, Cross-hauling and Dumping" forthcoming in the Journal of International Economics.

Lucas R.E. and M. Woodford., Real Effect of Monetary Shocks in an Economy with Sequential Purchases" NBER Working Paper No. 4250 , January 1993.

Prescott, Edward. C., "Efficiency of the Natural Rate" Journal of Political Economy, 83 (Dec. 1975): 1229-1236.

Williamson Oliver 0 . "Peak-Load Pricing and Optimal Capacity Under Indivisibility Constraints" The American Economic Review, Vol. 56, No.4 (Sep., 1966), pp. 810-827. 